\title{
Exercise testing in men with significant left main coronary disease ${ }^{1}$
}

\author{
J. V. NIXON, KIRK LIPSCOMB, C. GUNNAR BLOMQVIST, AND \\ WILLIAM SHAPIRO
}

\begin{abstract}
From the Cardiovascular Service, Veterans Administration Medical Center and the Adolph and Edith Weinberger Laboratory for Cardiopulmonary Research, Department of Internal Medicine of Southwestern Medical School, University of Texas Health Science Center, Dallas, Texas, USA
\end{abstract}

SUMMARY The exercise tests of 26 male patients with significant left main disease were compared with those of 51 patients with three-vessel disease and 38 patients with two-vessel disease. Exercise-induced ischaemia (chest pain and/or $>1 \mathrm{~mm}$ ST segment change) occurred in 100 per cent of left main, 69 per cent of three-vessel, and 45 per cent of two-vessel disease patients. Though the mean peak work load was significantly higher in the two-vessel disease group than in those with three-vessel or left main disease, there was a wide overlap between groups. No intergroup differences were found in mean peak heart rates. In patients taking propranolol, no differences in mean peak work loads and heart rates were seen.

The study showed that the absence of an exercise-induced abnormal electrocardiographic response virtually excludes left main disease. As judged by exercise performance, the presence of left main disease did not correlate with the severity of the patient's symptomatology. Propranolol did not influence the frequency of an ischaemic response in patients with left main or three-vessel disease.

Symptomatic patients with significant stenosis of the left main coronary artery are at higher risk of dying than patients without this lesion (Webster et al., 1974; Lim et al., 1975; Conley et al., 1978). It has been clearly established that coronary artery bypass surgery improves survival of these patients (DeMots et al., 1975; Takaro et al., 1976; Campeau et al., 1978). Thus, the identification of the patient with left main coronary stenosis is of paramount importance. Though selective coronary arteriography is the optimal method of determining the presence of this lesion, its expense and potential dangers prevent its routine use for screening the population at risk.

The electrocardiographic response to stress testing has been correlated with the location and severity of coronary disease (Cohn et al., 1972; McHenry et al., 1972; Goldschlager et al., 1976). A very ischaemic electrocardiographic response $(>2$ $\mathrm{mm}$ ST segment depression) has been reported to be a strong indicator of left main disease (Khaja

'Presented in part at the annual scientific session of the American Heart Association, Miami Beach, Florida, in December 1977.

Received for publication 6 April 1979 et al., 1974; Cheitlin et al., 1975; Cohen and Gorlin, 1975). However, in many laboratories, including our own, an ST segment change of $>1 \mathrm{~mm}$ is considered an indication for terminating the exercise test (Blomqvist, 1971). In these laboratories, a change of $>2 \mathrm{~mm}$ would be rarely seen even when left main disease is present.

Many clinicians have felt that the likelihood of left main disease is correlated with severe symptoms, and the decision whether or not to perform catheterisation, therefore, may be based on the clinical presentation. However, this premise is undocumented. Since the exercise test quantifies the limitations of physical work capacity imposed by typical angina pectoris, a comparison of the exercise test to the presence or absence of left main disease should clarify the supposition that left main disease, symptoms, and limitation to physical activity are correlated.

The purpose of the study was (a) to determine the value of the exercise test in predicting the presence or absence of left main disease, (b) to determine the correlation of the likelihood of left main disease with the severity of symptomatology, and (c) to determine to what extent betaadrenergic blockade affects the validity of the test. 


\section{Subjects and methods}

Between July 1973 and May 1977, 26 male patients with significant left main disease were studied by both cardiac catheterisation and exercise testing in our laboratory. Between July 1976 and May 1977, 51 male patients with significant three-vessel coronary disease and 38 male patients with twovessel disease were similarly studied by both catheterisation and exercise testing. These patient groups comprised all of the patients studied with a history of chest pain except for patients with electrocardiographic conduction abnormalities or ST segment changes associated with left ventricular hypertrophy. The mean age of the patients in all groups was 51 years.

Long-term oral propranolol was being taken by 7 patients with left main disease, 28 patients with three-vessel disease, and 21 patients with twovessel disease. No patients were taking other antiarrhythmic treatment or digoxin.

\section{EXERCISE TESTING}

Multistage ergometric exercise was performed using a Monark bicycle ergometer (Blomqvist, 1971; Nixon et al., 1978). The test was performed continuously starting at $150 \mathrm{kpm}(24.5$ watts) with a stepwise load increment increase of $150 \mathrm{kpm}$ (24.5 watts) every 3 minutes. The electrocardiogram was continuously monitored on a Hewlett Packard 1516A tape terminal attached to a Hewlett Packard 1309A oscilloscope, using a modification of Frank's orthogonal lead system (Blomqvist et al., 1965). Permanent recordings at $25 \mathrm{~mm} / \mathrm{s}$ were made before exercise, during the last 30 seconds of each level of exercise, and during the first 30 seconds of each post-exercise minute of observation for 5 minutes or until the electrocardiogram returned to its preexercise configuration. In addition, continuous $5 \mathrm{~mm} / \mathrm{s}$ recordings were obtained with a Marquette series 330 automatic strip chart recorder as a backup to the visual monitoring routine. Indirect blood pressure recordings were obtained at 1 -minute intervals throughout the study by the Doppler technique, using an Arteriosonde (Roche).

Each exercise test was aimed at 90 per cent of the patient's maximal predicted heart rate. Indications for premature termination of exercise in this laboratory include typical angina pectoris of any severity, electrocardiographic ST segment changes of $1 \mathrm{~mm}$ or greater, hypotension during any stage of exercise, ventricular premature beats occurring at a frequency of greater than 3 per minute, or fatigue requiring cessation of exercise (Blomqvist, 1971).

An electrocardiographic ischaemic response was considered positive if the ST segment depression was $>1 \mathrm{~mm}(0 \cdot 1 \mathrm{mV})$ below the level of the ST segment at rest and the depression was sustained for 0.08 second after the $\mathrm{J}$ point. The exercise tracings were read independently by at least 2 observers without knowledge of the clinical or catheterisation data of the patients. If a single observer considered the electrocardiographic ischaemic response to be questionable, it was deemed to be negative.

\section{CORONARY ARTERIOGRAPHY}

All patients underwent cardiac catheterisation within 3 days of their exercise test. Coronary arteriography was performed selectively by hand injection of Renografin 76 by the Judkins technique. Multiple projection coronary cineangiograms of each coronary artery were recorded on $35-\mathrm{mm}$ Eastman Double X negative cine film by a Roentgen $V$ camera at 60 frames per second.

The cinearteriograms were read independently by at least 2 observers without prior knowledge of the clinical or exercise data of the patients. Any single coronary artery was considered significantly stenosed if the luminal narrowing of the artery or one of its branches over $1.5 \mathrm{~mm}$ diameter was greater than 50 per cent of the vessel's diameter. When differences in interpretation existed, the arteriogram was evaluated by a third observer, and a consensus of 3 opinions was obtained.

The overall prevalence of left main disease in this laboratory relative to all studied patients with coronary disease is 9 per cent, which is approximately that found in other laboratories.

\section{DEFINITIONS}

The definitions of the terms used in this study are as follows. Prevalence is the proportion of patients in any study group who have disease. Sensitivity is the proportion of patients with disease who have a positive test. Specificity is the proportion of patients without disease who have a negative test. The predictive value of a positive test is the probability of patients having disease when the test is positive and may be calculated from the mathematical formula:

$$
\begin{aligned}
& \mathrm{P}(\mathrm{D}+/ \mathrm{T}+)=\mathbf{P}(\mathrm{T}+/ \mathrm{D}+) \mathbf{P}(\mathrm{D}+) \\
& \mathbf{P}(\mathrm{T}+/ \mathrm{D}+) \mathbf{P}(\mathrm{D}+)+\{1-\mathbf{P}(\mathrm{T}-/ \mathrm{D}-)\}\{1-\mathrm{P}(\mathrm{D}+)\}
\end{aligned}
$$

where $P(D+)$ is the probability of disease (D) before the test (T) is performed (prevalence), $\mathrm{P}(\mathrm{T}+/ \mathrm{D}+)$ is the probability of having a positive test when disease is present (sensitivity), and $\mathrm{P}(\mathrm{T}-/ \mathrm{D}-)$ is the probability of having a negative test when the disease is absent (McNeil et al., 1975). The predictive value of a negative test is the proba- 
bility of patients not having disease when the test is negative and, using the same symbols, may be calculated from the formula:

$$
\begin{aligned}
& \mathrm{P}(\mathrm{D}-/ \mathrm{T}-)=\mathbf{P}(\mathrm{T}-/ \mathrm{D}-) 1-\mathrm{P}(\mathrm{D}+) \\
& \mathbf{P}(\mathrm{T}-/ \mathrm{D}-)\{1-\mathrm{P}(\mathrm{D}+)\}+\mathrm{P}(\mathrm{D}+)\{1-\mathrm{P}(\mathrm{T}+/ \mathrm{D}+)\}
\end{aligned}
$$

\section{STATISTICAL ANALYSIS}

Values are expressed as means \pm standard errors of the mean (SE). Data were compared by analysis of variance. When significant differences $(P<0.05)$ were found, within-group differences were determined by the Student-Newman-Keuls multiple range test (Zar, 1974).

\section{Results}

\section{EXERCISE TESTS}

The Table summarises the endpoints of the exercise tests in each patient group. All patients with left main disease had either chest pain or electrocardiographic changes, and all but one of these patients $(96 \%)$ had electrocardiographic changes. This compared with 35 patients $(69 \%)$

\begin{tabular}{|c|c|c|c|c|c|c|}
\hline & \multicolumn{2}{|c|}{$\begin{array}{l}\text { Left main } \\
\text { disease } \\
(\mathrm{N}=26)\end{array}$} & \multicolumn{2}{|c|}{$\begin{array}{l}\text { Three-vessel } \\
\text { disease } \\
(\mathrm{N}=51)\end{array}$} & \multicolumn{2}{|c|}{$\begin{array}{l}\text { Two-vesse } \\
\text { disease } \\
(\mathrm{N}=38)\end{array}$} \\
\hline & & $\left(\begin{array}{l}0 \\
0\end{array}\right)$ & & $\left({ }^{0}{ }_{0}\right)$ & & $(\%)$ \\
\hline $\begin{array}{l}\text { Chest pain or } \\
\text { electrocardiographic }\end{array}$ & & & & & & \\
\hline abnormalities or both & 26 & $(100)$ & 35 & (69) & 17 & (45) \\
\hline Chest pain & 18 & $(69)$ & 26 & $(51)$ & 9 & (24) \\
\hline Electrocardiographic & & & & & & \\
\hline abnormalities & 25 & (96) & 24 & (47) & 12 & (32) \\
\hline $\begin{array}{l}\text { Chest pain and } \\
\text { electrocardiographic }\end{array}$ & & & & & & \\
\hline abnormalities & 17 & $(65)$ & 17 & (33) & 4 & (11) \\
\hline Fatigue & 0 & & 16 & (31) & 21 & (55) \\
\hline
\end{tabular}

Table Reasons for termination of exercise in each patient group

with three-vessel disease and 17 patients (45\%) with two-vessel disease who had either chest pain or electrocardiographic changes. In patients taking propranolol, an ischaemic response to exercise occurred in all 7 patients $(100 \%)$ with left main disease, 21 patients $(75 \%)$ with three-vessel disease, and 8 patients $(38 \%)$ with two-vessel disease. In patients not taking propranolol, an exerciseinduced ischaemic response occurred in all 19 patients with left main disease, 14 patients $(61 \%)$ with three-vessel disease, and 9 patients $(53 \%)$ with two-vessel disease.

Peak heart rates during exercise of all patients are shown in Fig. 1. No significant differences were found between mean values for patients with left

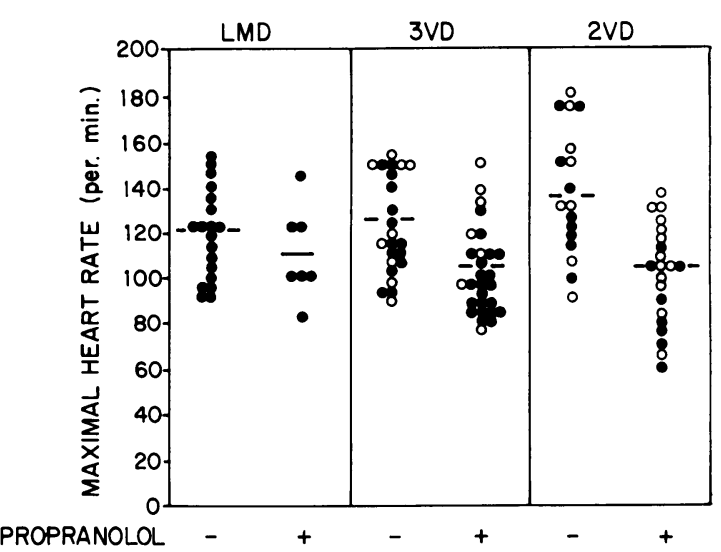

Fig. 1 Maximal heart rate response (beats per minute) during bicycle exercise in patients with left main disease (LMD), three-vessel disease (3VD), and two-vessel disease (2VD). Patients in each group separated into those taking (+) and not taking (-) propranolol therapy. Closed circles represent patients whose exercise tests were terminated by an ischaemic response (chest pain and/or electrocardiographic abnormalities), and open circles represent those who exercised to fatigue. Solid bars represent mean values.

main disease $(118 \pm 4$ beats $/ \mathrm{min})$, three-vessel disease $(114 \pm 3$ beats $/ \mathrm{min})$, or two-vessel disease $(120 \pm 4$ beats/min). Similarly, no significant differences were found between the three groups of patients taking propranolol (left main disease, $110 \pm 8$ beats/min; three-vessel disease, $104 \pm 3$ beats/min; two-vessel disease, $106 \pm 4$ beats $/ \mathrm{min}$ ), or not taking propranolol (left main disease, $120 \pm 4$ beats/min; three-vessel disease, $125 \pm 5$ beats/min; two-vessel disease, $138 \pm 7$ beats $/ \mathrm{min}$ ). In all instances, the spread of the individual data showed considerable overlap between the respective groups.

The work loads of all patients at the termination of exercise are shown in Fig. 2. Comparison of the mean values of all patients in each group showed significant differences $(\mathbf{P}<0.005)$. Intergroup analysis determined that while the mean values of patients with left main and three-vessel disease were similar, significant differences were present between values of patients with two-vessel disease $(474 \pm 27$ $\mathrm{kpm})$ and both left main disease $(342 \pm 29 \mathrm{kpm}$; $\mathrm{P}<0.001)$ and three-vessel disease $(386 \pm 32 \mathrm{kpm}$; $P<0.01)$. Similarly, significant differences were present when the mean peak work loads of patients not taking propranolol were compared $(P<0.005)$. Intergroup analysis showed a significant difference between mean values of the left main disease $(324 \pm 37 \mathrm{kpm})$ and the two-vessel disease group $(504 \pm 51 \mathrm{kpm} ; \quad P<0.005)$. No differences were seen between the left main disease and three-vessel disease $(402 \pm 22 \mathrm{kpm})$ or the three-vessel disease 


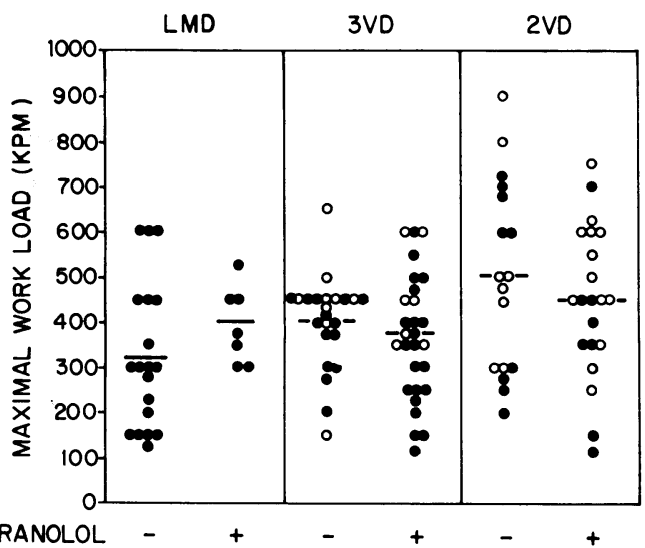

Fig. 2 Peak work load (kpm) during bicycle exercise in patients with left main disease (LMD), three-vessel disease (3VD), and two-vessel disease (2VD). Patients in each group separated into those taking (+) and not taking (-) propranolol therapy. Closed circles represent patients whose exercise tests were terminated by an ischaemic response (chest pain and/or electrocardiographic abnormalities), and open circles represent those who exercised to fatigue. Solid bars represent mean values $(1 \mathrm{kpm}=0.1635$ watt $)$.

and two-vessel disease groups. In patients taking propranolol, no differences were seen in the three groups (left main disease, $393 \pm 22 \mathrm{kpm}$; threevessel disease, $373 \pm 25 \mathrm{kpm}$; two-vessel disease, $449 \pm 37 \mathrm{kpm})$.

\section{DIAGNOSTIC POWER OF EXERCISE TESTING}

When electrocardiographic changes alone were used as the determinant of a postive exercise test, the sensitivity of the test was 96 per cent and the specificity was 60 per cent for patients with left main disease in this group of patients with coronary artery disease. Using this sensitivity and specificity in conjunction with the left main disease prevalence of 9 per cent among all patients with coronary artery disease, the predictive value of a positive exercise test is calculated to be 19 per cent, and the predictive value of a negative test to be 99 per cent. In other words, a patient who has a 9 per cent probability of having left main disease before an exercise test has a 19 per cent probability after a positive test and a 1 per cent probability after a negative test.

When the determinant of a positive exercise test was chest pain and/or electrocardiographic changes at a work load of $300 \mathrm{kpm}$ or less, the sensitivity of the test was reduced to 54 per cent but the specificity increased to 85 per cent. Referring this sensitivity and specificity to the 9 per cent prevalence of left main disease, the predictive value of a positive test was 26 per cent, a small increase over that due to electrocardiographic changes alone. However, the predictive value of a negative test dropped considerably from 99 to 95 per cent.

\section{Discussion}

The results of this study confirm that in patients with stable angina pectoris, the exercise test is useful in evaluating the presence or absence of significant left main disease. Conspicuously ichaemic ST segment responses of $2 \mathrm{~mm}$ or greater during exercise testing are considered to be very suggestive of left main disease (Khaja et al., 1974; Cheitlin et al., 1975; Cohen and Gorlin, 1975). However, in our laboratory, an ST segment change of $1 \mathrm{~mm}$ or greater is taken as evidence of ischaemia and is an indication for termination of exercise (Blomqvist, 1971). Thus, it is pertinent to determine the predictive values of positive and negative tests using this criterion for termination of the test. As one might expect, our study has shown that a positive test will not single out this group of patients. However, the more important question is whether coronary arteriography is necessary purely to determine whether left main disease is present. Our data indicate that the probability of left main disease is only 1 per cent if significant exercise-induced electrocardiographic changes do not occur. Furthermore, not only were all the patients studied male but all had symptoms of chest pain and angiographically documented coronary artery disease. Thus, when referred to the general population, the prevalence of left main disease of 9 per cent used in this study to determine the predictive values of the exercise test is an overestimate and the actual predictive values are even higher.

Several studies have correlated the frequency and magnitude of the electrocardiographic response to exercise with the location and severity of coronary disease (Cohn et al., 1972; McHenry et al., 1972; Goldschlager et al., 1976). Other exercise indices such as threshold heart rates and work loads have been shown to correlate with the extent of coronary disease (Blomqvist et al., 1978; Chaitman et al., 1978; McNeer et al., 1978). Thus, as reported by McNeer and co-workers (1978), patients with left main disease are expected to have more frequent ischaemic responses at lower peak work loads than patients with less extensive disease. In our study, the frequency of an exercise-induced ischaemic response in the respective patient groups concurred with previous findings, being highest in the left main disease group and lowest in the two-vessel disease group. However, peak heart rates and work loads did not correlate as accurately as has been previously reported. When all patients in each group were considered, no significant differences in mean 
peak heart rates of the three groups were found. Similar statistical analysis of mean peak work loads showed a significant difference only in the twovessel disease group, with no difference shown between the groups with left main and three-vessel disease. Furthermore, the distribution of threshold work loads of the left main disease patients showed little difference from the patients with threevessel and two-vessel disease. These latter findings are in line with those of Blomqvist et al. (1978), who reported that while group differences existed between left main or three-vessel disease patients when compared with patients with less extensive disease, the wide intra- and intergroup overlap of these exercise measurements precluded a clinical conclusion with respect to any individual patient. In our patients, when $300 \mathrm{kpm}$ was arbitrarily selected as a representative low peak load, the probability of having left main disease after a positive test at this threshold changed a little, whereas the probability of having this lesion after a negative test increased from 1 to 5 per cent. Thus, the presence or absence of an exercise-induced ischaemic response at a lower heart rate or work load failed to distinguish patients with left main disease from those with three-vessel and twovessel disease.

One possible reason for the differences in our findings compared with other reports may be the inclusion of patients on propranolol therapy. The influence of long-term propranolol treatment on exercise performance and haemodynamics is well known. Though it has a direct depressant action on myocardial contractility, the overall effect of propranolol during exercise is to lower cardiac work by reducing the heart rate and systemic blood pressure response (Wolfson and Gorlin, 1969; Nixon et al., 1978). Furthermore, it has been reported that, in the same patients, angina pectoris was the endpoint of exercise more frequently during the placebo phase than during the therapeutic phase of oral propranolol administration (Alderman et al., 1975). In this latter report, however, the extent of each individual patient's coronary disease was not identified. In other studies correlating the frequency of exercise-induced ST segment changes with the severity of documented coronary artery disease, the effects of propranolol, if any, were either not subject to comment or the patients were excluded from the study (Cohn et al., 1972; Goldschlager et al., 1976; McNeer et al., 1978).

Our data showed that propranolol therapy did not affect the frequency of an ischaemic response in patients with left main disease and three-vessel disease. In patients with three-vessel disease, the frequency was increased in those on propranolol. Conversely, the frequency of an ischaemic response in two-vessel disease patients was less in those on propranolol therapy. However, the significant difference in mean peak work load in patients with two-vessel disease compared with left main and three-vessel disease was abolished by propranolol administration. In addition, there was a wide overlap between each patient group with respect to individual peak work loads and heart rates. Thus, while propranolol did not affect the frequency of an ischaemic response to exercise in patients with more severe and extensive disease, it abolished any differences in other exercise indexes that may be used to distinguish the extent and severity of coronary artery disease.

Many clinicians feel that the incidence of left main disease correlates with the patients' symptomatology. Thus, within the restrictions of the exercise test procedure, an exercise-induced ischaemic response would be expected to occur at a comparatively low work load in these patients (Blomqvist, 1971; McHenry and Fisch, 1977). Our data show that this is not so. There was a wide distribution in individual peak work loads and overlap between each patient group, especially in those patients on propranolol therapy. It seems unlikely that, as judged by exercise performance, the symptoms of an individual patient could be used as an indicator of the presence or absence of left main disease.

This study has shown that, in patients with stable angina pectoris, the exercise test is useful in assessing patients with significant left main disease. The absence of an electrocardiographic response to exercise virtually excludes the possibility of left main disease. Propranolol therapy did not reduce the frequency of an ischaemic response to exercise in patients with left main or three-vessel disease, but abolished any differences in peak work loads that might be useful in distinguishing the extent of a patient's coronary artery disease. The likelihood of the presence of left main disease did not appear to correlate with the severity of the patient's symptomatology as judged by their exercise performance.

\section{References}

Alderman, E. L., Davies, R. O., Crowley, J. J., Lopes, M. G., Brooker, J. Z., Friedman, J. P., Graham, A. F., Matlof, H. F., and Harrison, D. C. (1975). Dose response effectiveness of propranolol for the treatment of angina pectoris. Circulation, 51, 964-975.

Blomqvist, C. G. (1971). Use of exercise testing for the diagnosis and functional evaluation of patients with arteriosclerotic heart disease. Circulation, 44, 1120-1136.

Blomqvist, C. G., Astrand, I., and Messin, R. (1965). Clinical physiological and electrocardiographic findings in patients with angina pectoris during work in cold environment and during arm work. Acta Medica Scandinavica, 178, Suppl. $440,74-81$. 
Blomqvist, C. G., Gaffney, F. A., Atkins, J. M., Nixon, J. V., Mullins, C. B., and Willerson, J. T. (1978). The exercise ECG and related physiological data as markers of critical coronary artery lesions. Acta Medica Scandinavica, 203, Suppl. 615, 52-61.

Campeau, L., Corbara, F., Crochet, D., and Petitclerc, R. (1978). Left main coronary stenosis: the influence of aortocoronary bypass surgery on survival. Circulation, 57, 1111-1115.

Chaitman, B. R., Bourassa, M. G., Wagniart, P., Corbara, F., and Ferguson, R. J. (1978). Improved efficiency of treadmill exercise testing using a multiple lead ECG system and basic hemodynamic exercise response. Circulation, 57, 71-79.

Cheitlin, M. D., Davis, J. E., DeCastro, C. M., Barrow, E. A., and Anderson, W. T. (1975). Correlation of 'critical' left coronary lesions with positive submaximal exercise tests in patients with chest pain. American Heart fournal, 89, 305-310.

Cohen, M. V., and Gorlin, R. (1975). Main left coronary artery disease: clinical experience from 1964-1974. Circulation, 52, 275-285.

Cohn, P. F., Vokonas, P. S., Most, A. S., Herman, M. V., and Gorlin, R. (1972). Diagnostic accuracy of two-step postexercise ECG. Results in 305 subjects studied by coronary arteriography. Fournal of the American Medical Association, 220, 501-506.

Conley, M. J., Ely, R. L., Kisslo, J., Lee, K. L., McNeer, J. F., and Rosati, R. A. (1978). The prognostic spectrum of left main stenosis. Circulation, 57, 947-952.

DeMots, H., Boncher, L. I., Rösch, J., Anderson, R. P., Starr, A., and Rahimtoola, S. H. (1975). Left main coronary disease: risks of angiography, importance of coexisting disease of other coronary arteries and effects of revascularization. American fournal of Cardiology, 36, 136-141.

Goldschlager, N., Selzer, A., and Cohn, K. (1976). Treadmill stress tests as indicators of presence and severity of coronary artery disease. Annals of Internal Medicine, 85, 277-286.

Khaja, F., Sharma, S. D., Easley, R. M., jun, Heinle, R. A., jun, and Goldstein, S. (1974). Left main coronary artery lesions: risk of catheterization, exercise testing and surgery (abstract). Circulation, 49 and 50, Suppl. II, 136-140.
Lim, J. S., Proudfit, M. L., and Sones, F. M., jun. (1975). Left main coronary arterial obstruction: long-term follow-up of 141 nonsurgical cases. American fournal of Cardiology, 36, 131-135.

McHenry, P. L., and Fisch, C. (1977). Clinical applications of the treadmill exercise test. Modern Concepts of Cardiovascular Disease, 46, 21-25.

McHenry, P. L., Phillips, J. F., and Knoebel, S. B. (1972). Correlation of computer-quantitated treadmill exercise electrocardiogram with arteriographic location of coronary artery disease. American fournal of Cardiology, 30, 747-752.

McNeer, J. F., Margolis, J. R., Lee, K. L., Kisslo, J. A., Peter, R. H., Kong, Y., Behar, V. S., Wallace, A. G., McCants, C. B., and Rosati, R. A. (1978). The role of the exercise test in the evaluation of patients for ischemic heart disease. Circulation, 57, 64-70.

McNeil, B. J., Keeler, E., and Adelstein, S. J. (1975). Primer on certain elements of medical decision making. New England Fournal of Medicine, 293, 211-215.

Nixon, J. V., Pennington, W., Ritter, W. S., and Shapiro, W. (1978). Efficacy of propranolol in the control of exerciseinduced or augmented ventricular ectopic activity. Circulation, 57, 115-122.

Takaro, T., Hultgren, H. N., Lipton, M. J., Detre, K. M., and Participants in the Study Group. (1976). The VA Cooperative randomized study of surgery for coronary arterial occlusive disease. II. Subgroup with significant left main lesions. Circulation, 53 and 54, Suppl. III, 107-117.

Webster, S., Moberg, C., and Rincon, G. (1974). Natural history of severe proximal coronary artery disease as documented by coronary cineangiography. American Fournal of Cardiology, 33, 193-200.

Wolfson, S., and Gorlin, R. (1969). Cardiovascular pharmacology of propranolol in man. Circulation, 40, 501-511.

Zar, J. H. (1974). Biostatistical Analysis. Prentice-Hall, Englewood Cliffs, New Jersey.

Requests for reprints to Dr J. V. Nixon, Cardiovascular Service, VA Medical Service, 4500 South Lancaster Road, Dallas, Texas 75216, USA. 